
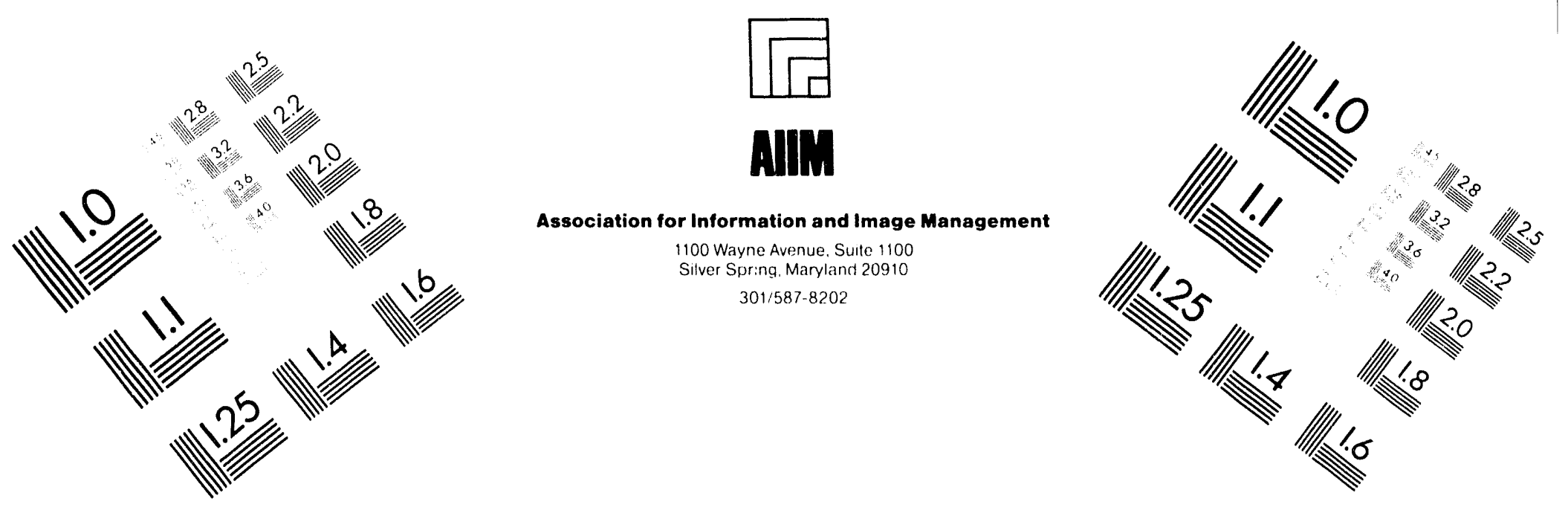

\title{
Centimeter
}

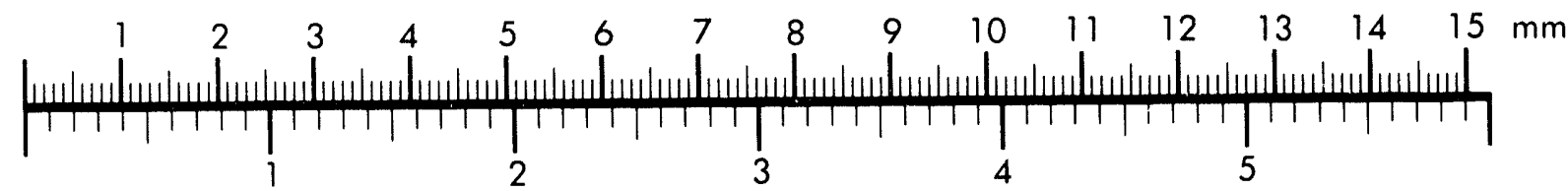

Inches
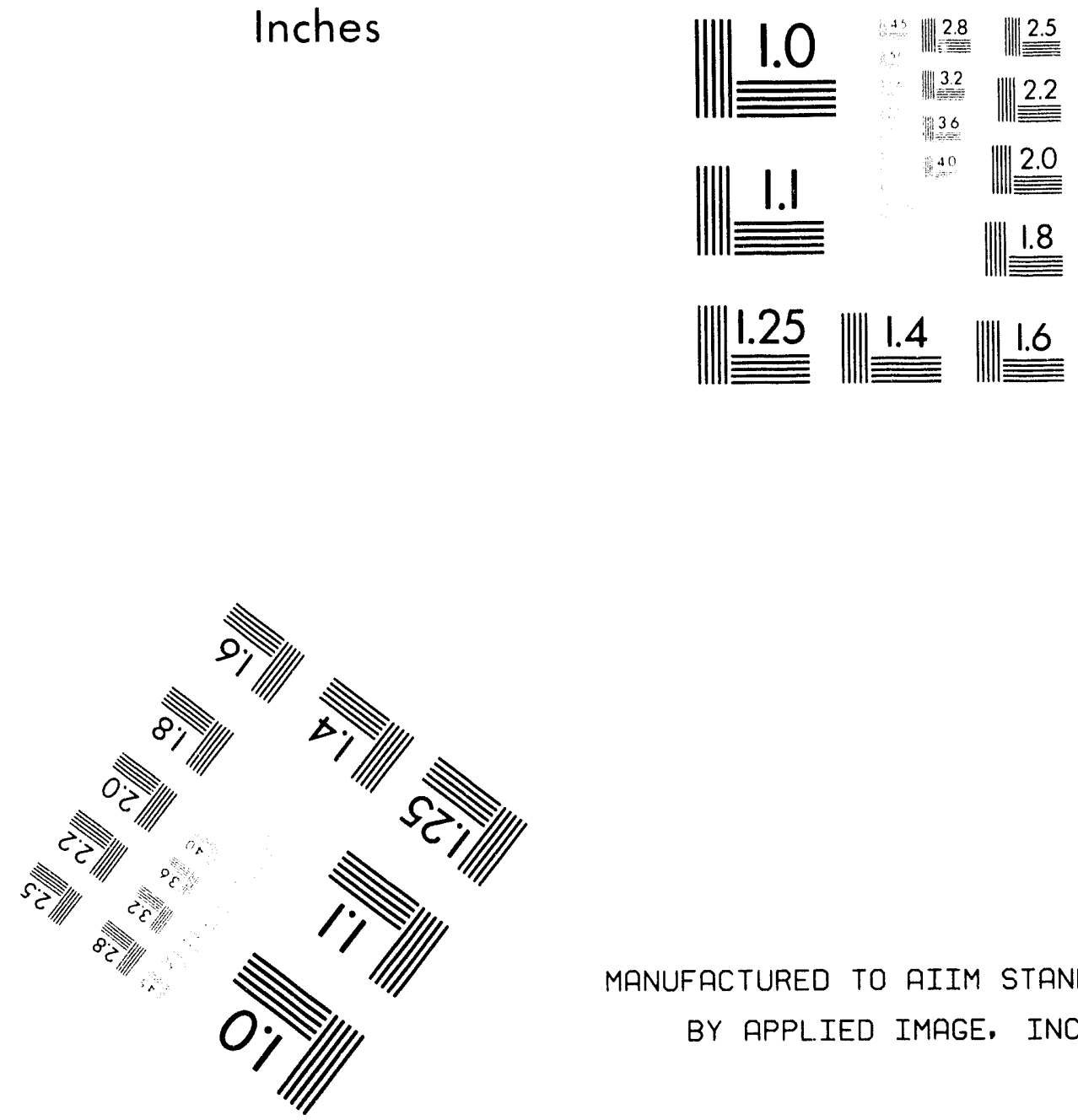

MANUFACTURED TO AIIM STANDARDS

BY APPLIED IMAGE. INC.

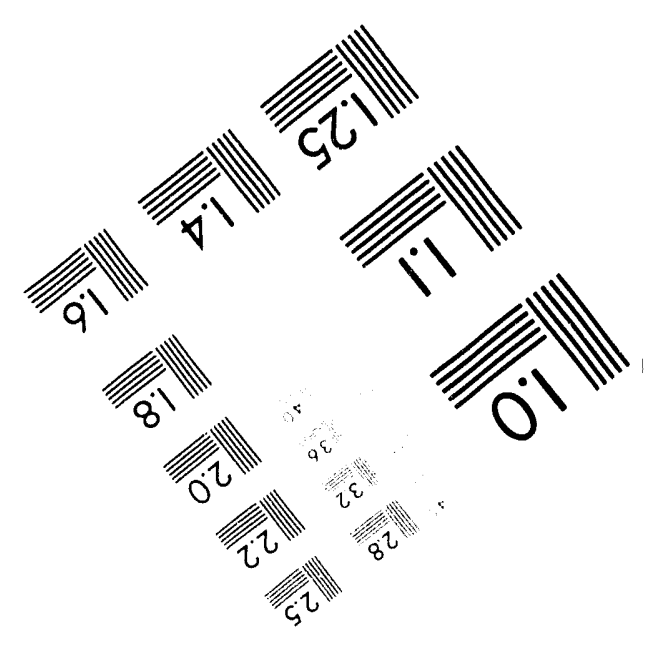



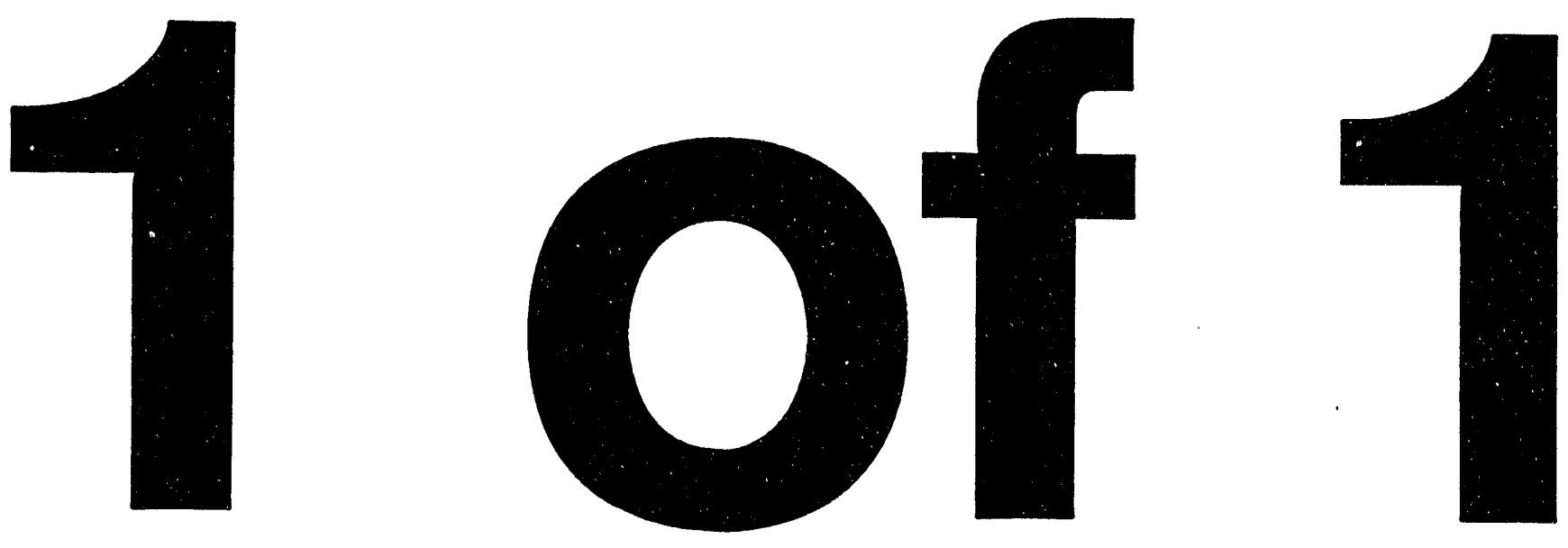


\section{HW- 65482}

Cover Sheet for a Hanford Historical Document Released for Public Availability

Released 1994

Prepared for the U.S. Department of Energy under Contract DE-AC06-76RLO 1830

Pacific Northwest Laboratory Operated for the U.S. Department of Energy by Battelle Memorial Institute 


\section{DISCLAIMER}

This is a historical document that is being released for public availability. This was made from the best available copy. Neither the United States Government nor any agency thereof, nor Battelle Memorial Institute, nor any of their employees, makes any warranty, express or implied, or assumes any legal liability or responsibility for the accuracy, completeness, or usefulness of any information, apparatus, product, or process disclosed, or represents that its use would not infringe privately owned rights. The views and opinions of authors expressed herein do not necessarily state or reflect those of the United States Government or any agency thereof. 


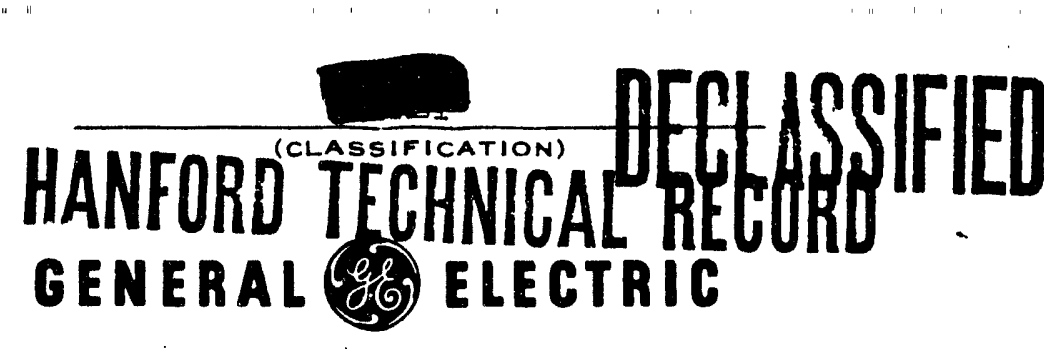

HANFORD ATOMIC PRODUCTS OPERATION - RICHLAND, WASHINGTON

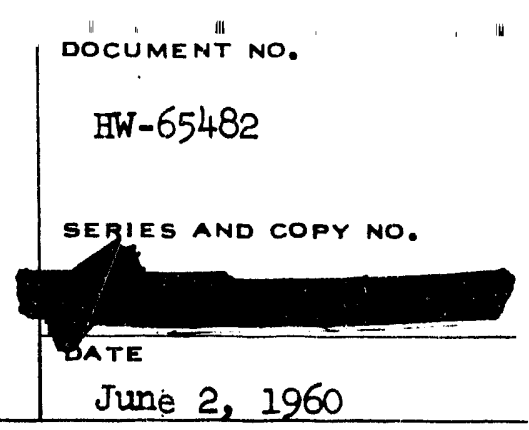

TITLE

ANTICIPATED HEAT GENERATION RATE OF MGCR-III FUEL EIEMENT AS A FUNCTION OF ENRICHMENT

\section{AUTHOR}

W. L. Bunch

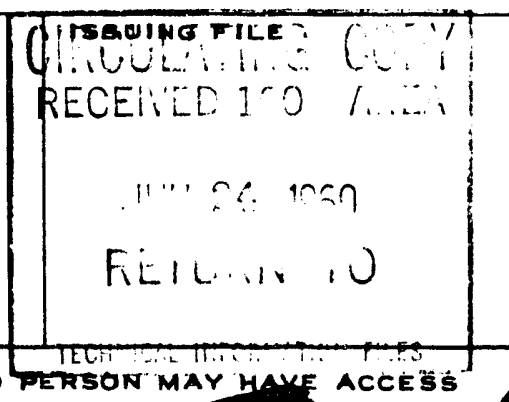

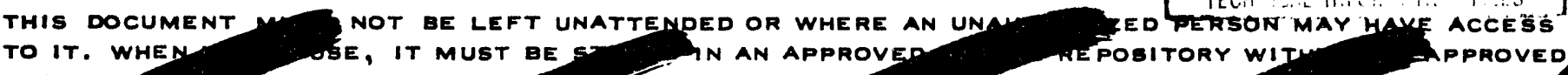

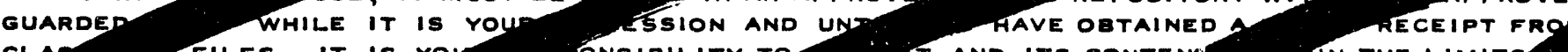
CLA FILES, IT IS YON DONSIBILITY TO "IT AND ITS CONTEN MUJECT AND FROM RESIDENCE IS PQ? D. IT IS NOT IS TRANSMITTAL TO MIN THE LIMITE TORAGE AT YOUP CEE DUPLICATED. IF ONAL COPIES ARE IRED, OBTAIN THEM FRO RELATED ISSL TO SIGN IN Th CE PROVIDED BELOW.

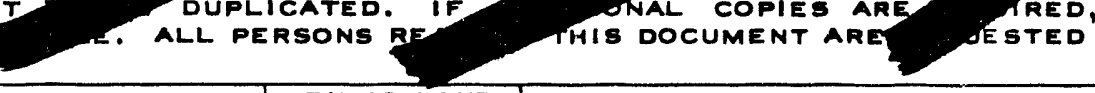

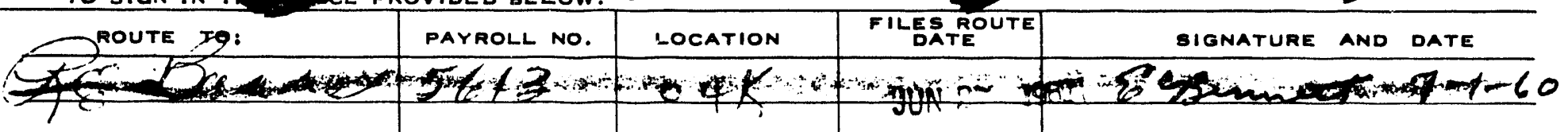

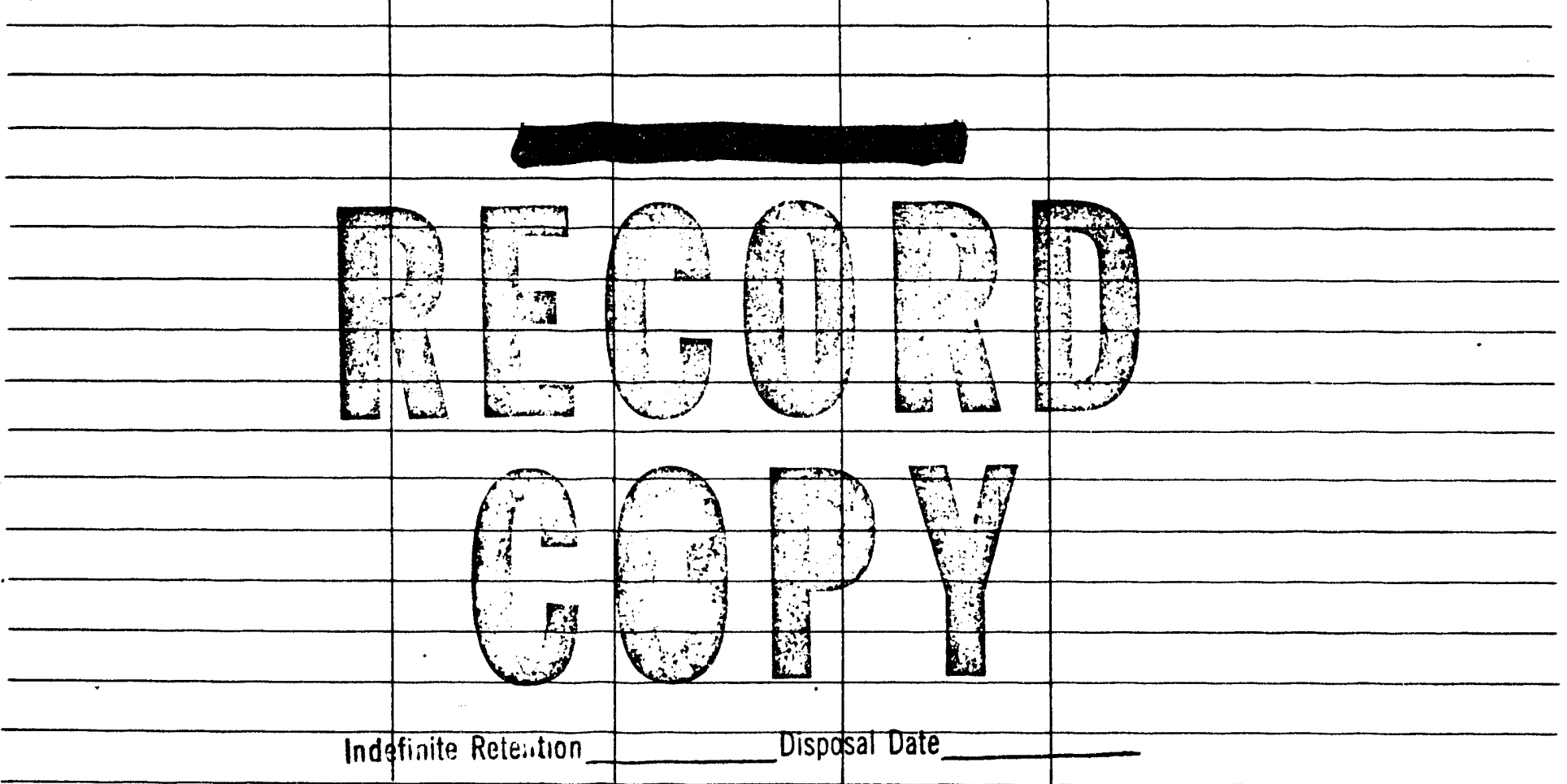

$54-3000-340(3-57) \quad$ Arc.GE miAuibuldily Authority

(CLASSIFICATION) 
1. AEC-HOO,Attr:RL Plum

2. AEC-HOO,Attn:RI Plum

3,4,5. General Atomic, Division of General Dynamics Corporation Sen Diego, Califormia

Attention: HC Hopkins, Jr.

6. RE Baars

7. EC Bennett

8. WL Bunch

9. CE Fitch

10. FC Franklin

11. GC Fullmer-GF Owsley

12. AK Hara1n-MR Moon

13. DS Lewis

14. CG Lewis

15. RK Marshall

16. DG Montague

17. $R$ Nilson

18. KW ReiduSM Graves

19. HG Speucer

20. RE Trumbie

21. FW Van Wormer

22. 300 File

23. Record Copy
This document classified by

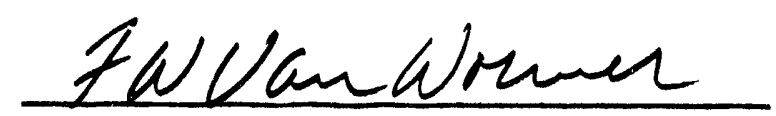

This document consists of 13 pages.

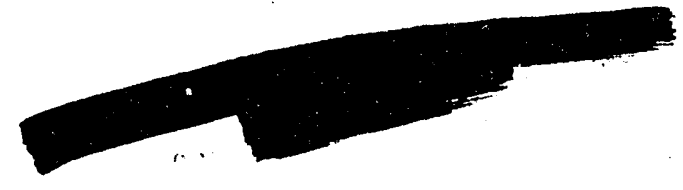

June 2, 1960

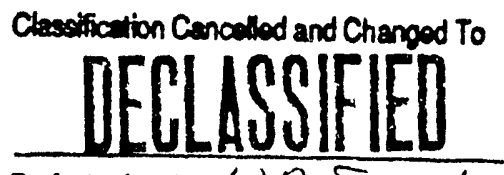

By Authority of LA, 5 yetas $P R-24,2-2-44$ By Esamk $218-44$ verifed By Queshi niclesthi a $2-94$ is report was prepared for use within General Electric Company in the course $3^{2} 2-94$ of work under Atomic Energy Commission Contrect/4 T(4) $-1 / 55$ and any views or opinions expressed in the report are those of the authors only. This report is subject to revision upon collection of additional data.

\section{LEGAL NOTICE}

This report was prepared as an account of Government sponsored work. Neither the United States, nor the Commission, nor any person acting on behalf of the Commission:

A. Makes any warranty or representation, express or implied, with respect to the accuracy, completeness, or usefulness of the information contained in this report, or that the use of any information, apparatus, method, or process disclosed in this report may not infringe privately owned rights; or

B. Assumes any liabilities with respect to the use of, or for damages resulting from the use of any information, apparatus, method, or process disclosed in this report.

As used in the above, "person acting on behalf of the Commission" includes any employee or contractor of the Commission to the extent that such employee or contractor prepares, handles or distributes, or provides access to, any information pursuant to his employment or contract with the Commission.

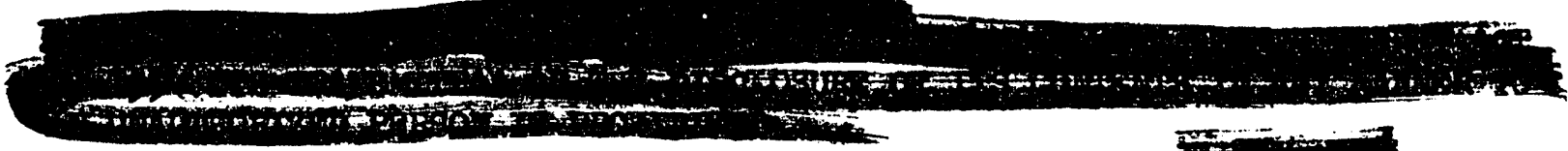




\section{DECLLSSFFIED}

HW -65482

ANTICIPATED HEAT GENERATION RATE OF MGCR-III FUEL ELEMENT AS A FUNCTION OF ENRICHMENT

\section{INIRODUCTION}

The DR-1 Loop, located in the C test hole of the DR Reactor, provides a high temperature, recirculating gas-cooled facility for the irradiation of experimental fuel elements. The loop is being utilized currently by General Atomic, a Division of General Dynamics, to evaluate fuel elements in support of their work on the Maritime Gas-Cooled Reactor Program, a program which is directed at the development of a ship propulsion unit consisting of a gas-cooled reactor driving a closed cycle gas turbine. The loop irradiations for this program require that the experimental fuel elements be maintained at specific test conditions. It is alsu necessary that all of the loop components be kept within certain operating limits. Therefore, the power generation rate of each experimental fuel element must be evaluated and established as accurately as possible prior to insertion in the loop. One method of establishing the enrichment required to obtain a required heat generation rate in an experimental element is to irradiate a nuclear mock-up of the assembly in the Hanford Test Reactor to determine the relative neutron density within the assembly and the reactor. This report presents the results of such irradiations using the MGCR-III mock-up.

\section{SUMMARY}

Previous engineering studies have established the criterion that the heat generation rate of the MGCR-III element should be 40 kilowatts to maintain desirable conditions in both the element and the loop. The HTR irradiations indicate that a 14.25 inch long fueled body of the type used should contain approximately 45 grams of U-235 in the form of enriched uranium oxide or should contain approximately 40 grams of U-235 if ceramic ${ }^{*}$ fuel pellets are used. Uncertainty in the heat generation rate at a given level of enrichment is expected to be about plus 15 per cent and minus 25 per cent. The bulk of this uncertainty is due to the temperature correction which must be applied to extrapolate the HTR data to the actual high temperatures which will exist in the loop. Some uncertainty is associated also in forecasting reactor operating conditions six months to a year in advance. Figure 1 presents the results of the five irradiations which were made in the HTR using the MGCR-III mock-up.

\section{DISCUSSION}

\section{A. Background}

The in-reactor portion of the DR-I Loop consists of a sealed inconel pressure tube located in the $C$ test hole and extending slightly beyond the midplane of the reactor from the experimental level side. Within this pressure tube is a concentric flow tube which contains the experimental fuel element being irradiated. The coolant gas enters through the annulus between the tubes and returns through the fuel element and the flow tube to the out-ofreactor equipment located on the $x-1$ Level. The out-of-reactor equipment includes the filters, heat exchangers, pumps and pre-heaters necessary to supply a regulated and controlled flow of gas coolant to the in-reactor assembly. Experimental fuel elements irradiated within the facility are designed to operate at specific temperatures; these temperatures can be regulated to a certain extent by controlling the flow rate and temperature of the coolant gas. Because of the complex heat balance system which exists

*Ceramic pellets refers to the tested fuel which was $45.8 \mathrm{w} / 0 \mathrm{Al}_{2} \mathrm{O}_{3}$ and $54.2 \mathrm{w} / 0 \mathrm{UO} 2$.

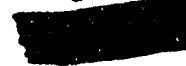




\section{DECLASSFFED}

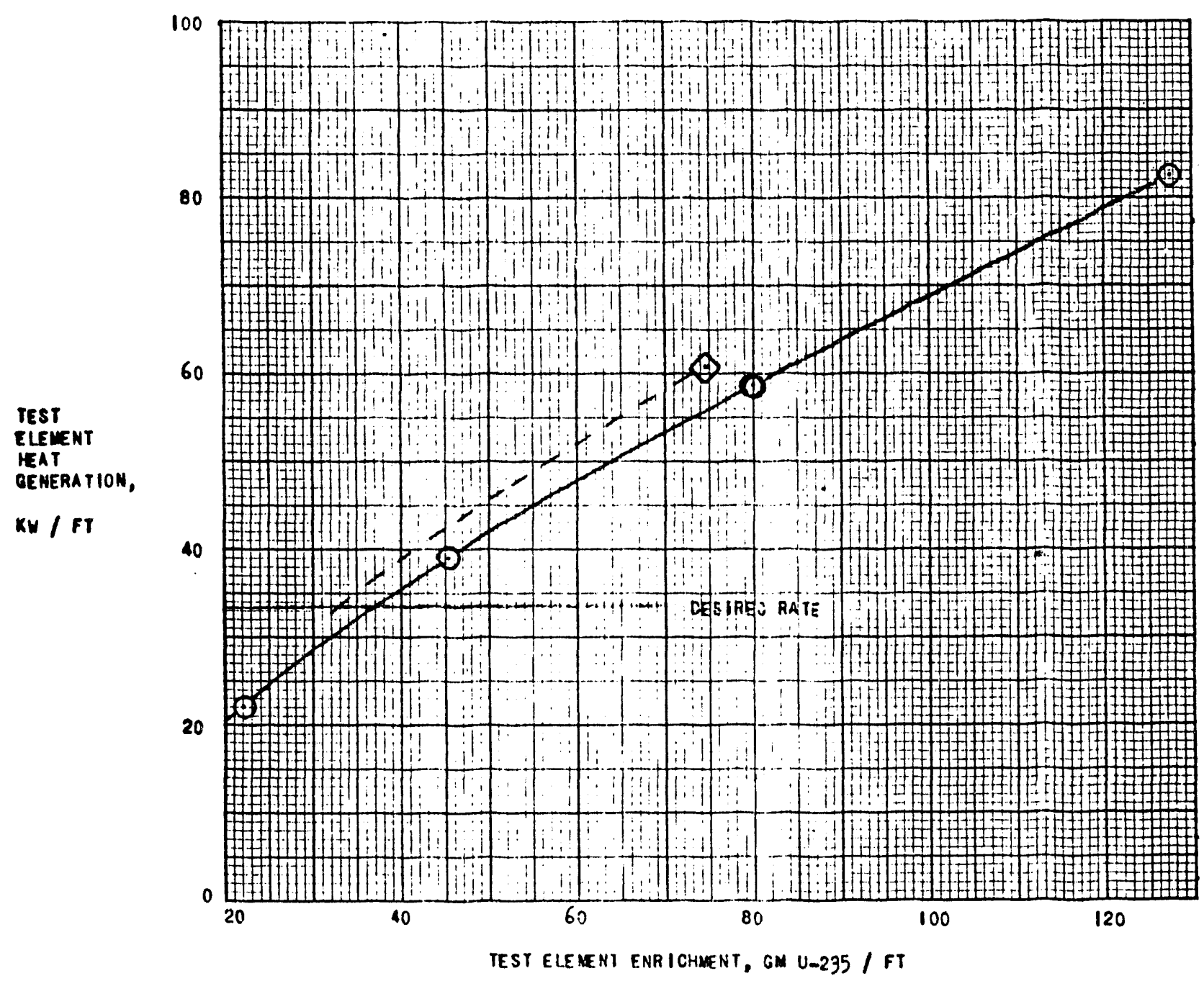

FIGURE ।

EXPECTEC HEAT GENERATION RATE OF THE MGCR-3

TEST ELEMENT IN THE DR-I LOOP AS A FUNCTION OF ENRICHMENT

- - U URANIUM OXIOE FIEL

$-\prec-$ ceramic fuel

$-3-$ 
(interchange of heat between the annulus and core coolant, between the tube and the graphite stack, between the tube and the shield step plug, gamma heating in the pressure and flow tubes, etc.) and because of the many locations whose temperature must be regulated (the experimental fuel element, the in-reactor pressure tube wall, inlet to the pumps, preheater outlet, etc.) it is necessary to consider each proposed experimental fuel element independently and to establish an optimum heat generation rate for the element which will best meet all of the requirements of the loop and the planned test. For the proposed MGCR-III element it has been determined previously that the heat generation rate should be 40 kilowatts.

The maclear mock-up of the MGCR-III fuel element proposed for future Irradiation in the DR-1 Loop is shown in Figure 2. The mock-up element consists of a nineteen-rod cluster arranged on a hexagonal array with the central rod being a dummy or blank tube. Of the eighteen fueled rods, six are at the corners of the array, six lie along the faces of the array, and six are within the inner ring of the array. The length of the fissionable material within each tube is to be 14.25 inches with a nominal diameter of 0.350 inches. The fuel will be either enriched uranium oxide or a ceramic element composed of enriched uranium oxide and some other material such as aluminim oxtde. Four different uranium oxide fuels were irradiated in the present tests plus one ceramic fuel.

\section{B. Basis for Experiments}

The amount of fission heat removed by the coolant passing through a test assembly can be calculated by the equation:

$$
(I) P_{t}=\bar{\phi}_{t} N_{t} \sigma H f_{t} c(1+\delta)_{t}
$$

where $P_{t}=$ kilowatts of heat removed by the coolant

$\bar{D}=$ the volume average conventional neutron flux in the test element

$N_{t}=$ the number of atoms of $\mathrm{U}-235$ contained in the test element

$\sigma=$ the fission cross section of U-235 for 2200 meter per second neutrons

$\mathrm{H}=$ the heat of fission, in Mev

$f_{t}=$ the fraction of the fission heat which is removed by the coolant

$c=$ energy conversion constant, $1.6 \times 10^{-16}$ kilowatt seconds per Mev

$(1+\delta)_{t=a}$ factor to account for the fast fission events which are induced in the U-238 contained within the test element.

Each of these factors is known or can be calculated or obtained with a fair degree of confidence except for the value of the volume average neutron flux. The Hanford Test Reactor is used to obtain the relationship between the volume average neutron flux in the test element and in the adjacent production uranium. The power generation in the adjacent

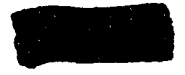




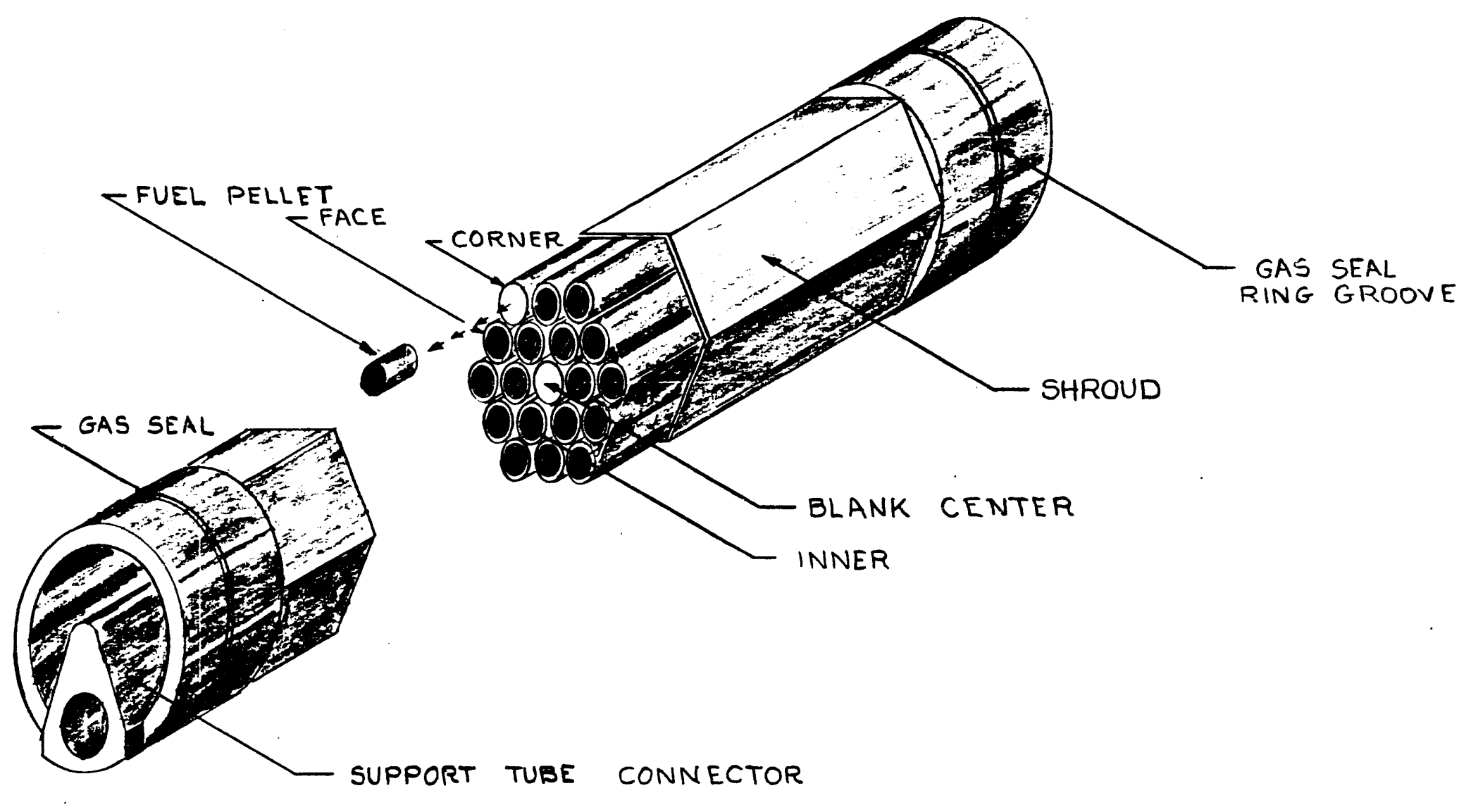

FIGURE 2
NUCLEAR MOCK - UP
MGCR-III
$-5-$


production uranium can in turn be used to establish the absolute value of the neturon flux. In the HTR an experimental determination is made of a rise factor, $R$, which is defined as the ratio of the volume average flux in the test element to the unperturbed flux incident on the adjacent process tube, 1.e.

$$
R=\bar{\phi}_{t} / \phi_{s}
$$

where $\phi_{s}$ is the unperturbed flux which would be incident on the process tube at that point if the experimental mock-up were not present. The unperturbed flux incident on the surface of the tube can in turn be related to the volume average flux in the entire charge of metal within the tube by a consideration of three factors: 1) the water blocking effect, $W$, 2) the disadvantage factor $D$, and 3 ) the location factor, $L$.

The water blocking effect takes into account the drop in thermal flux which occurs across the water annulus between the process tube and the surface of the canned uranium slug. The disadvantage factor takes into account the difference betwreen the volume average flux within an internally and externaliy cooled uranium piece and the flux incident on the outer surface of the piece. The location factor takes into account the flux distribution which exists along the length of the adjacent production uranium channel, 1.e., the local volume average flux compared to the overall volume average flux in the uranium. Combining these factors:

$$
\text { (2) } \bar{\phi}_{t}=R I D W \bar{\phi}_{a d j}
$$

where $\bar{\phi}_{\mathrm{adj}}$ is the volume average flux in the metal in the production column adjacent to the loop. This flux value $\left(\bar{\phi}_{\mathrm{adj}}\right)$ can be obtained from the unperturbed heat generation rate of an adjacent tube (or from the average unperturbed value of a number of adjacent tubes) using the same heat generation expression as for the test element where the subscript "adj" indicates a tube adjacent to the loop. Thus,

$$
\text { (3) } \Phi_{a d j}=P_{a d j} / N_{a d j} \cdot \sigma_{H} f_{a d j} c(1+\delta)_{a d j} \cdot
$$

Combining equations (1), (2), and (3), it is found that the amount of fission heat removed by the coolant passing through the test element becomes:

$$
\text { (4) } P_{t}=R \text { L D W P adj } N_{t} / N_{a d j}
$$

if it is assumed that $f_{t}$ and $f_{a d j}$ are equal and that the fast fission factors are essentially equal. This equation gives the power generation for the test element for the temperature distribution which existed in the HTR during the rise factor experiments. As the media are differentially heated, the neutron density distribution undergoes a significant change due to the differential changes in the absorption cross sections of the several elements present. Introducing a temperature correction factor, $T$, yields the following heat generation equation for the test element:

$$
\text { (5) } P_{t}=R I D W T P_{\text {adj }} N_{t} / N_{a d j} \text {. }
$$


c. Experimental Determination of $R$ as a Function of Fuel Loading

The Hanford Test Reactor is a critical facility which is used routinely for quality control of production uranium and graphite. It is fueled with natural uranium and is graphite moderated with a square lattice pitch similar to the production reactors. Although differences exist between the HIR and the DR Reactor it is felt thrit the neutron spectrum and density distribution within the cells of the two reactors should be quite similar so that HTR experiments can be used to estimate neutron fluxes within the gas loop. A two-foot long mock-up of the loop pressure tube and flow tube had been made previously from the actual materials used in the loop. This mock-up, enclosing a nuclear mock-up of a proposed experimental fuel element, can be inserted into a side test hole of the HIR such that the geometrical configuration is essentially ldentical to the actual loop.

As defined above, the rise factor which is to be determined from the HTR irradiations is the ratio of the volume average flux in the test element to the unperturbed flux incident on the adjacent process tube at that point. The relative radioactivity of copper foils is used to determine this ratio. In the MGCR-III test element these copper folls were placed within the fuel tubes between the fuel pellets so that the relative volume average neutron density within that particular fuel tube could be obtained directly. The unperturbed neutron flux incident on the fuel in the process tube adjacent and transverse to the test element mock-up was obtained by placing foils on the surface of the uranium charged into that tube. The flux in the vicinity of the loop mock-up was perturbed severely by the presence of the mock-up; therefore, the unperturbed value was obtained from the radioactivity of foils irradiated at some distauce (three to five feet) from the mock-up. This normalization was based on the known unperturbed flux distribution which exists in the HTR. The relative radioactivity of all of the folls was determined with a ganma spectrometer. Count rate data were corrected for background, decay, instrument factor, and sample weight in addition to the normalization based on position in the reactor during the irradiation.

A typical set of experimental results is shown in Figures 3 and 4 . Figure 3 presents the front-to-rear traverse obtained from the folls irradiated on the surface of the canned uranium pieces. It can be seen that at distances greater than about two feet from the mock-up the flux is essentially unperturbed. Figure 4 presents the data obtained in the 1.5 per cent enriched uranium oxide loading. Note that copper foil data were also obtained on the surface of the fuel element, on the surface of the flow tube and on the surface of the pressure tube. These data indicate that mock-up end effects are negligible in the fuel assembly and also clearly show the varlation in neutron density which is related to the pitch of the lattice cell. Table I sumarizes the experimental rise factors for each of the fuels irradiated. Corner, face, and inner are the terms used to describe the location of the fuel: tube within the hexagonal array. Based on the consistency of the data these values are judged to be accurate to better than 3 per cent at the 90 per cent confidence level. 


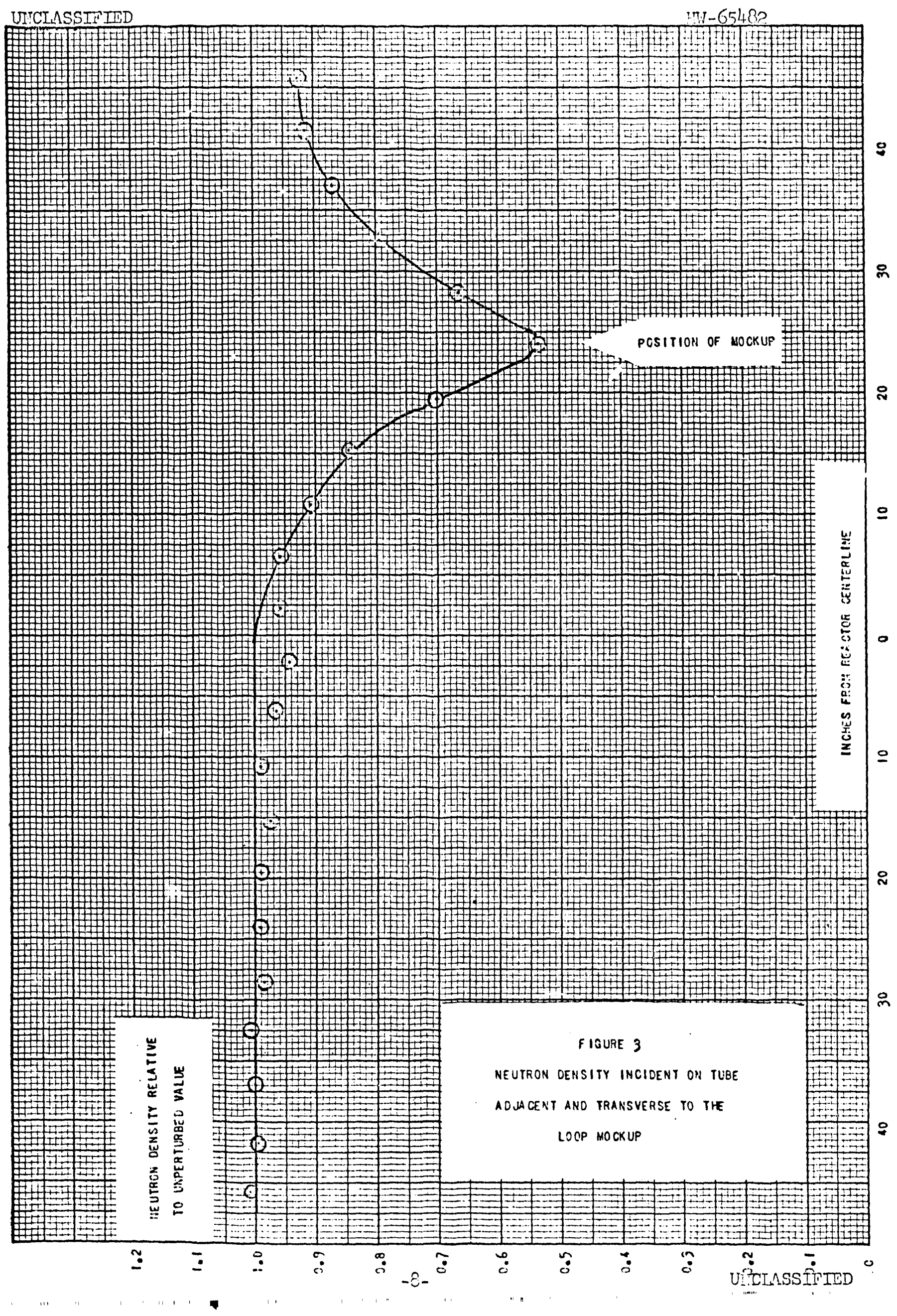




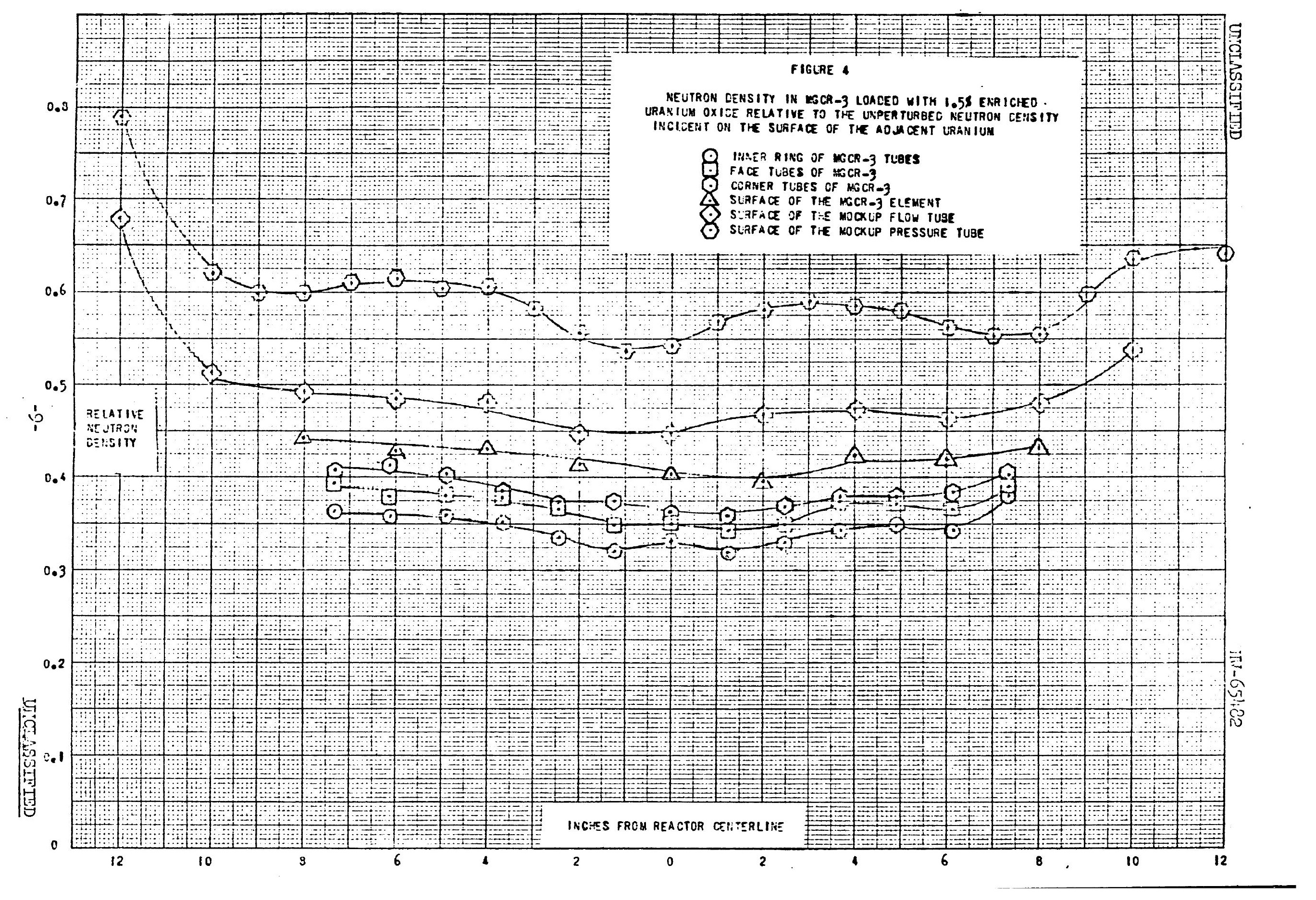


TABLE I

EXPERIMENTAL RIST FACTORS AS A FUNCTION OF FUEL LOADING

$\begin{array}{llllll}\text { Fuel Loading } & \text { Cormer } & \text { Face } & \text { Inner } & \begin{array}{c}\text { Central } \\ \text { (blank) }\end{array} & \begin{array}{c}\text { Fuel } \\ \text { Average }\end{array} \\ \begin{array}{llllll}\text { Natural uranium } \\ \text { oxide }\end{array} & 0.434 & 0.426 & 0.406 & 0.405 & 0.422 \\ 1.5 \% \text { enriched } & 0.384 & 0.369 & 0.345 & 0.344 & 0.366 \\ 2.61 \% \text { enriched } & 0.344 & 0.322 & 0.268 & 0.265 & 0.311 \\ 4.3 \% \text { enchriched } & 0.301 & 0.275 & 0.249 & 0.233 & 0.275 \\ \text { Ceramic } & 0.366 & 0.352 & 0.315 & 0.302 & 0.344\end{array}$

D. Estimation of Enrichment Used in Experiments, $N_{t}$

The actual U-235 content of the mock-up fuel element is subject to some uncertainty because of the random length of the fuel pellets and the impossiblifty of exactly filling each fuel tube. An average effective length of the pellets in a particular loading was measured and the number of pellets required to fill a foot long section of the element calculated. This number of pellets divided by the total number of pellets which were recelved times the quantity of U-235 transferred by the shipping report gives the enrichment loading per loot of element. This method was felt to be most accurate because it accounts for the actual spacing which existed in the experiments due to non-square ends, the looseness or tightness with which they were loaded, etc. In the case of the $1.5 \%$ enriched material, the welght, length, and diameter of the entire loading was measured and the average density calculated to be 10.7 grams per cubic centimeter. This value agrees quite well with densities which should be expected for uranium oxide. Calculated U-235 loadings for each of the experiments is given in Table II.

TABIE II

CAALCULATED U-235 CONTENT AS A FUNCTION OF FUEL LOADING

\section{Fuel Loading}

Natural uranium oxide

$1.5 \%$ enriched

2.61 \% enriched

$4.3 \%$ enriched

Ceramic
Weight $(\mathrm{g} / \mathrm{ft})$

22.2

$45 \cdot 3$

80.0

$127 \cdot 5$

74.8
$\underline{N}_{t}$ (atoms U235/ft)

$$
0.0569 \times 10^{24}
$$

0.116

0.205

0.327

0.192

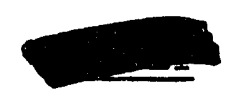


E. Evaluation of Other Parameters

The rate of fission heat removed from the test element can be calculated using the above experimental values and the best available values for the extrapolation factors $I, D, H . T, N_{a d j}$, along with the predicted value for $P_{a d j}$ during the irradiation period. The following values have been used:

a. The location factor, L

The location factor is calculated to be 1.40. This value is based on the effective cosine distribution which exists in a 32-piece charge of metal and the relative location of the $C$ test hole with respect to this distribution. Under normal operating conditions the uncertainty in this value is only a few percent. During unusual conditions, such as flux cycles, it is known that the value can deviate quite markediy. At this location in the reactor it is felt that a deviation greater than 10 per cent is unlikely.

\section{b. The disadvantage factor, D}

Calculations based on experimental parameters yleld a value of 1.15 for the disadvantage factor for the currently used production metal. It is felt that this value is within 5 per cent of the actual value.

c. The water blocking effect, $W$

The water blocking effect has been measured and calculated to be 1.15 with an uncertainty of less than 4 per cent.

d. The temperature correction factor, $T$

No method has been found to date to evaluate the temperature correction factor accurately. A paramount difficulty encountered in obtaining a tempe rature correction. factor is the inability to determine the actual temperature distribution which exists in the vicinity of the loop. Even if the actual temperature distribution were known the temperature effect could not be calculated at the present time because of the complex geometrical relationships which would need to be considered. However, in order that the temperature effect might be estinated, a numerical calculation was made based on an estimated pelitron temperature distribution and using an existing P-3 program. (1) The calculated temperature correction factor was 0.9. Based on the results of the MGCR-I Irradiation It would appear that the value is probably too high. It is felt that the uncertainty in the number may be as great as plus 10 per cent and minus 20 per cent. The evaluation of the temperature correction factor is truly the weak link in the current utilization of HTR mock-ups for loop power evaluation.

(1) HW-60781, "Program on the IBM 709 Digital Computer of the P-3 Approximation to the Boltzman Transport Equation in Cylindrical Geometry" D. D. Matsamoto and C. R: Richey, 6-7-59 
e. The adjacent tube power, $P_{a d j}$

The prognostication of the unperturbed adjacent tube power during the course of the planned irradiation some six months from now is based on current operating plans. Operating level of the reactor is limited administratively. It is planned to replace the current 34-piece charges with 32 piece charges and to utilize block discharges which will maintain the number of effective central tubes at approximately 1600 . Using an historical 'region factor' it is predicted that the adjacent tube power will be approximately: 1070 kilowatts during the irradiation. The uncertainty in this value is estimated to be about 5 per cent at the 90 per cent confidence level.

f. The U-235 content of an adjacent tube, $\mathrm{N}_{\text {adj }}$

This value also is based on the changeover to a 32-piece charge of 7.4 pound natural uranium elements. The calculated U-235 content per tube is $1.94 \times 1024$ atoms.

F. Results

The comination of the above factors yields the following equation for estimating the amount of heat to be removed by the coolant from the experimental fuel element as a function of the rise factor and the enrichment:

$$
P_{t}=919 \mathrm{R} \mathrm{N}_{t} 10^{-24}
$$

Table III presents the estimated heat generation rates of the proposed element as a function of enrichment based on the experimental rise factors obtained from the HTR Irradiations and the calculated U-235 content of the assembly during the irradiations. These values are also shown in Figure I. Note that the values are per foot of fueled length; for a 14.25 inch fueled length the heat rate would be 1.1875 times as great.

\section{TABLE III}

ESTIMATED HEAT REMOVAL RATE FROM MGCR-III AS A FUNCTION OF ENRICHMENT

\begin{tabular}{|c|c|c|c|}
\hline \multirow{2}{*}{$\begin{array}{l}\text { Fuel Loading } \\
\text { Natural uranium } \\
\text { oxide }\end{array}$} & $\begin{array}{c}\mathrm{R} \\
\text { Rise Factor } \\
\end{array}$ & 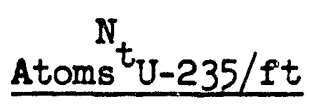 & $\underset{\mathrm{kw} / \mathbf{f t}_{\mathrm{t}}}{\mathrm{P}_{\mathrm{t}}}$ \\
\hline & 0.422 & $0.0569 \times 10^{24}$ & 22.1 \\
\hline $1.5 \%$ enriched & 0.366 & 0.116 & 39.0 \\
\hline 2.61 \% enriched & 0.311 & 0.205 & 58.6 \\
\hline 4.3 \% enriched & 0.275 & 0.327 & 82.6 \\
\hline ceramic & 0.344 & 0.192 & 60.7 \\
\hline
\end{tabular}

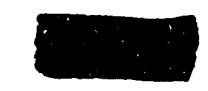


It can be seen that the rise factor for the ceramic element is somewhat greater than for an oxide of similar U-235 content making the heat generation rate approximately 10 per cent greater. This difference is attributed to the moderating effect of the ceramic filler.

The combined uncertainties of the parameters which enter into the calculation of $\boldsymbol{P}_{t}$ indicate that the values should be valid to within about plus 15 per cent and minus 25 per cent. As might be expected, the bulk of this uncertainty is due to the temperature correction factor. Significant uncertainty is also associated with the actual operating conditions which will exist during the irradiation.

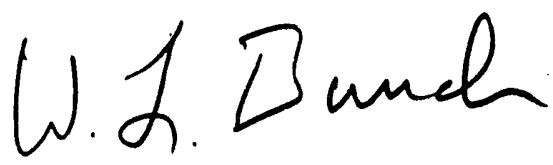

W. L。 Bunch

Irradiation Testing

WLB: bmr 

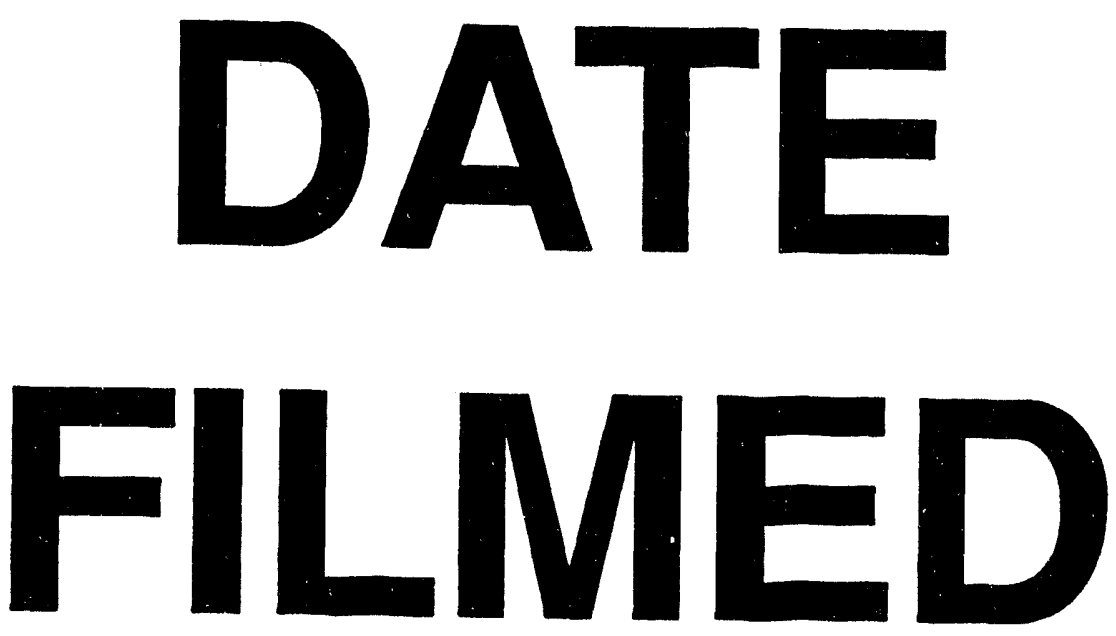

$6 / 23 / 94$
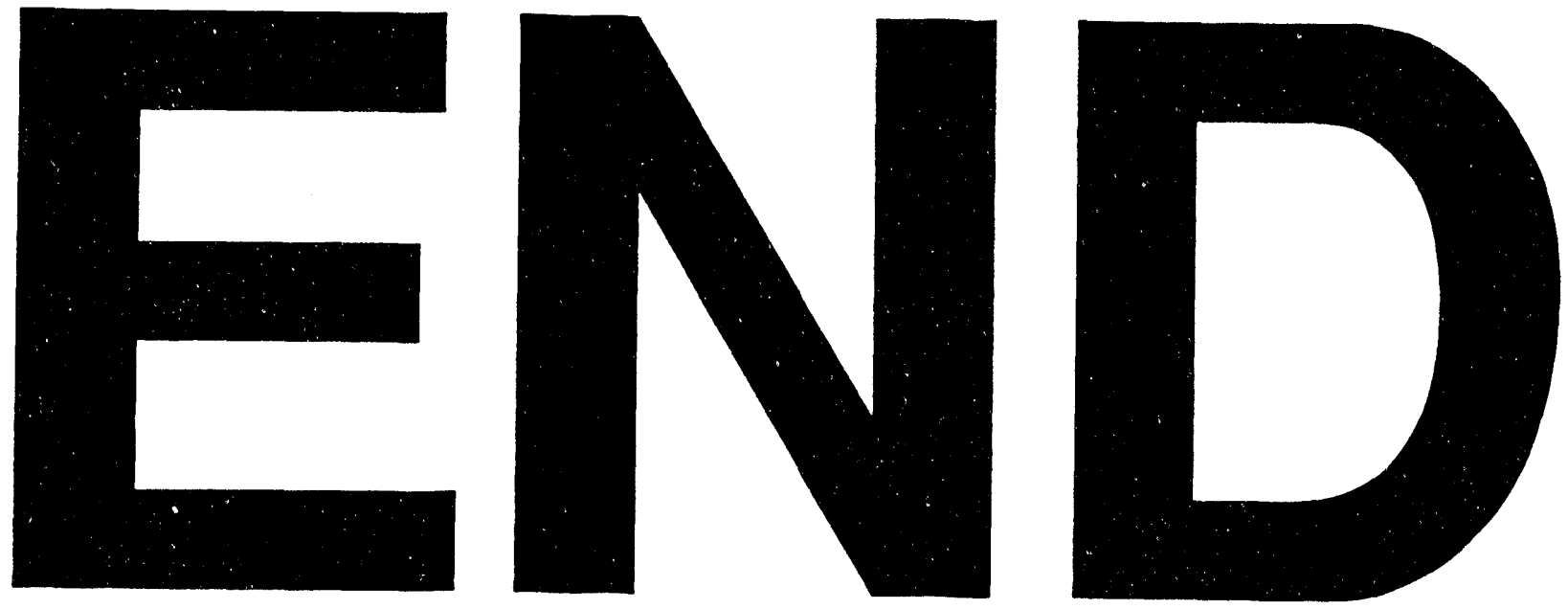
